\title{
Neurofibroma of the trachea: a case report
}

\author{
A. THIJS-VAN NIES ${ }^{1}$, B. VAN DE BREKEL ${ }^{2}$, H. J. BUYTENDIJK ${ }^{1}$, AND F. MAESEN \\ From the Department of Respiratory Diseases ${ }^{1}$ and the Ear, Nose, and Throat Department ${ }^{2}$, \\ de Wever-Ziekenhuis, Heerlen, The Netherlands.
}

Thijs-van Nies, A., van de Brekel, B., Buytendijk, H. J., and Maesen, F. (1978). Thorax, 33, 121-123. Neurofibroma of the trachea: a case report. A tracheal tumour was discovered by radiology in a 36-year-old man with haemoptysis, bronchitis, and dyspnoea. The tumour was situated $5 \mathrm{~cm}$ below the vocal cords. A frozen section of a bronchoscopic biopsy specimen confirmed it to be a neurofibroma. Resection was performed endoscopically.

Neurofibromata, benign tumours originating in the endoneurium or neurilemma (the sheath of Schwann), can theoretically arise in all innervated tissues and organs but in the trachea they are of the greatest rarity (Link, 1964).

The only case report of a neurofibroma of the trachea we have found was by Secrétan and de Weck (1953).

A similar tumour is described in this paper.

\section{Case report}

On 1 July 1976 a 36 -year-old man was seen in the outpatient clinic.

He complained of morning cough and bloodstained sputum, which he attributed to his smoking habit (over 25 cigarettes daily for 15 years). Four years previously he had been treated with antibiotics, whereupon his symptoms disappeared. Chest radiography was then normal. He now complained of increasing shortness of breath on exercise and after bouts of coughing, and a highpitched whistling in the throat on coughing. Treatment with antibiotics was ineffective. There was inspiratory stridor, increasing after coughing.

On clinical examination no other abnormality was found. Lymph nodes were not palpable.

The results of laboratory investigations were all normal. Sputum culture grew Haemophilus influenzae.

\section{SPIROMETRY}

The results of spirometric tests are shown in the Table. Forced vital capacity (FVC), forced expiratory volume in one second $\left(\mathrm{FEV}_{1}\right)$, and transfer factor (steady state method) (DLCO) were normal. The peak expiratory flow rate (PEFR) and maximal expiratory flow rate at $25 \%$ vital capacity
Table Results of spirometric tests

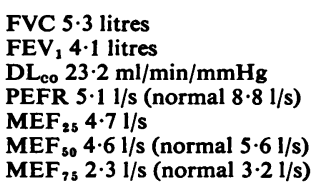

$\left(\mathrm{MEF}_{25}\right)$ were considerably reduced, and the $\mathrm{MEF}_{50}$ and $\mathrm{MEF}_{75}$ were reduced to a lesser degree.

These values could be explained by higher bronchial obstruction, for example, foreign body or tumour (Miller and Hyatt, 1973).

\section{RADIOLOGICAL EXAMINATIONS}

The chest radiograph was normal. In the anteroposterior tracheal radiograph there was a rounded shadow, $1.8 \mathrm{~cm}$ diameter, located in the centre of the trachea over the intervertebral space between $\mathrm{C}_{7}$ and $\mathrm{T}_{1}$ (Fig. 1). The lateral view showed a bilobar swelling $5 \mathrm{~cm}$ below the vocal cords (Fig. 2).

\section{CLINICAL PROGRESS}

The patient was admitted to the chest unit of the hospital on 5 July 1976.

Bronchoscopy under general anaesthesia revealed a greyish-red, lobed, shiny tumour the size of a marble, $5 \mathrm{~cm}$ below the vocal cords, attached to the posterolateral tracheal wall by a stalk, almost completely obstructing the tracheal lumen. A frozen section was reported to show a benign neurofibroma with a number of very well defined neurinoma structures containing cellular bundles of connective tissue with palisading of the nuclei. Between the nodules showing the neurinoma structures (Antoni type A) (Fig. 3) there is loose tissue 


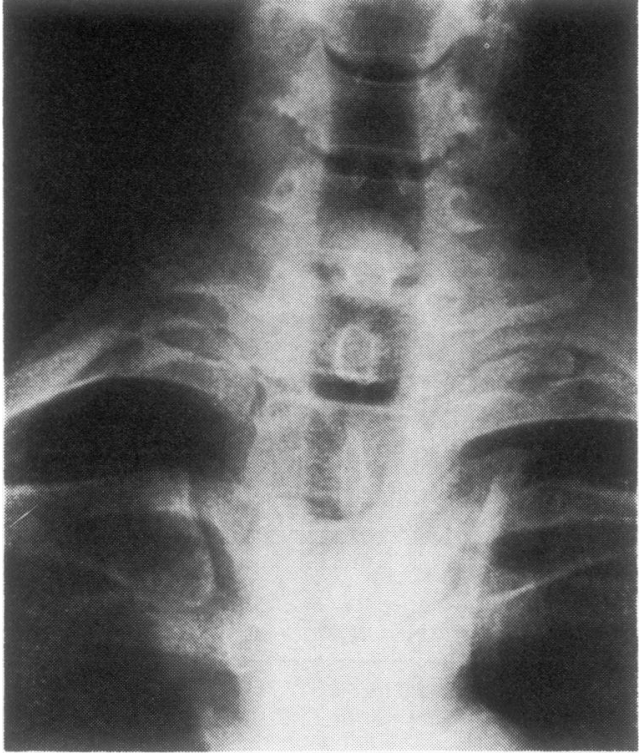

Fig. 1 Anteroposterior tracheal radiograph. Rounded shadow, $1.8 \mathrm{~cm}$ diameter, in front of the intervertebral space between $C_{7}$ and $T_{1}$.

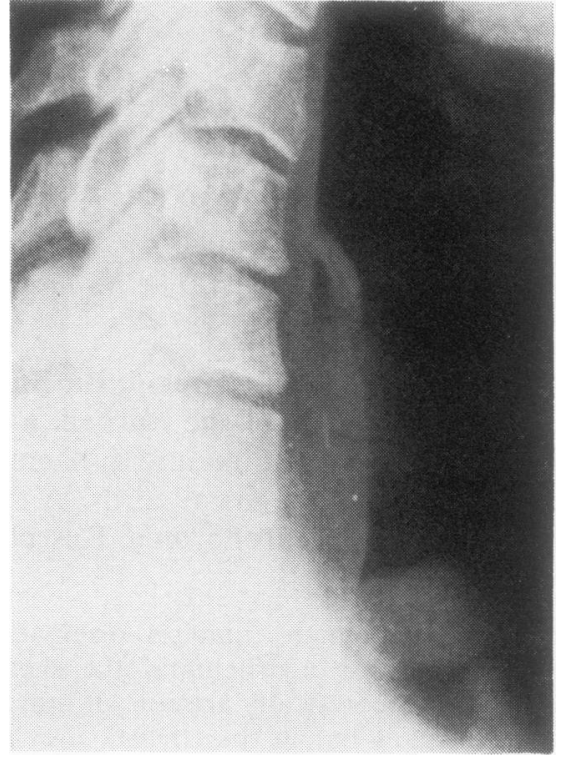

Fig. 2 Lateral tracheal radiograph. Bilobar shadow in lower section of trachea.

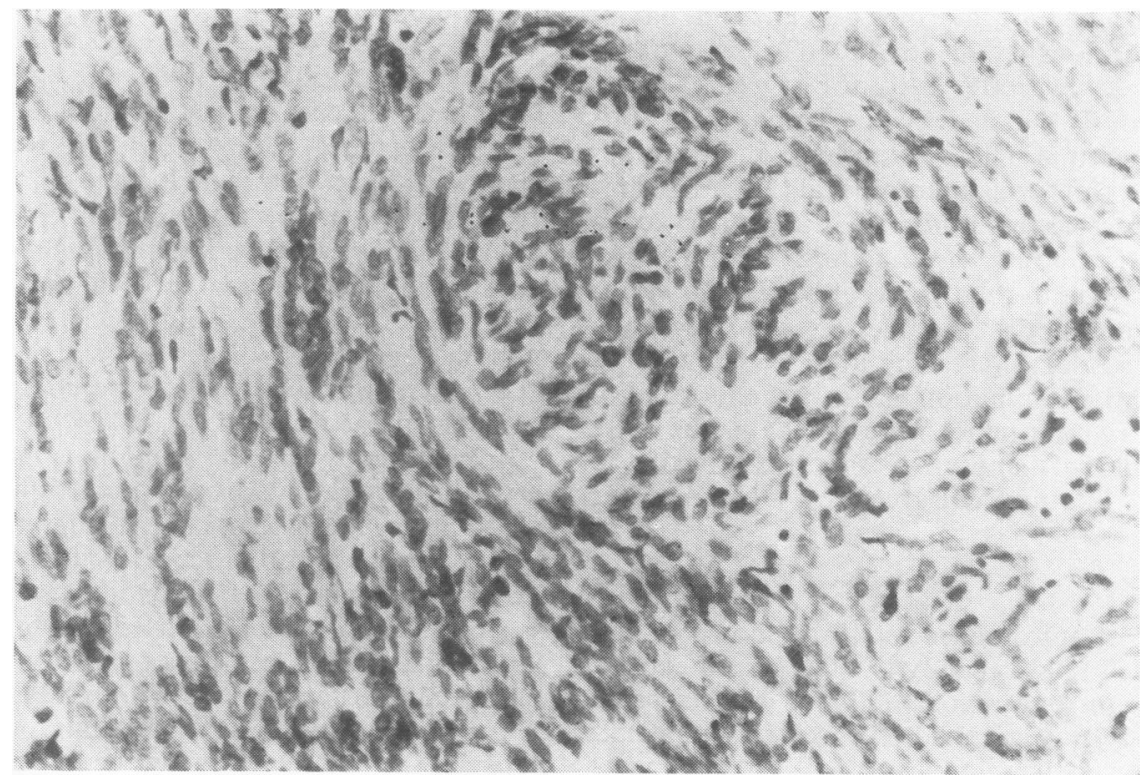

Fig. 3 Histology of tumour. Cellular bundles of connective tissue with nuclear palisading (Antoni type A) (Haematoxylin and eosin $\times 250$ ). 


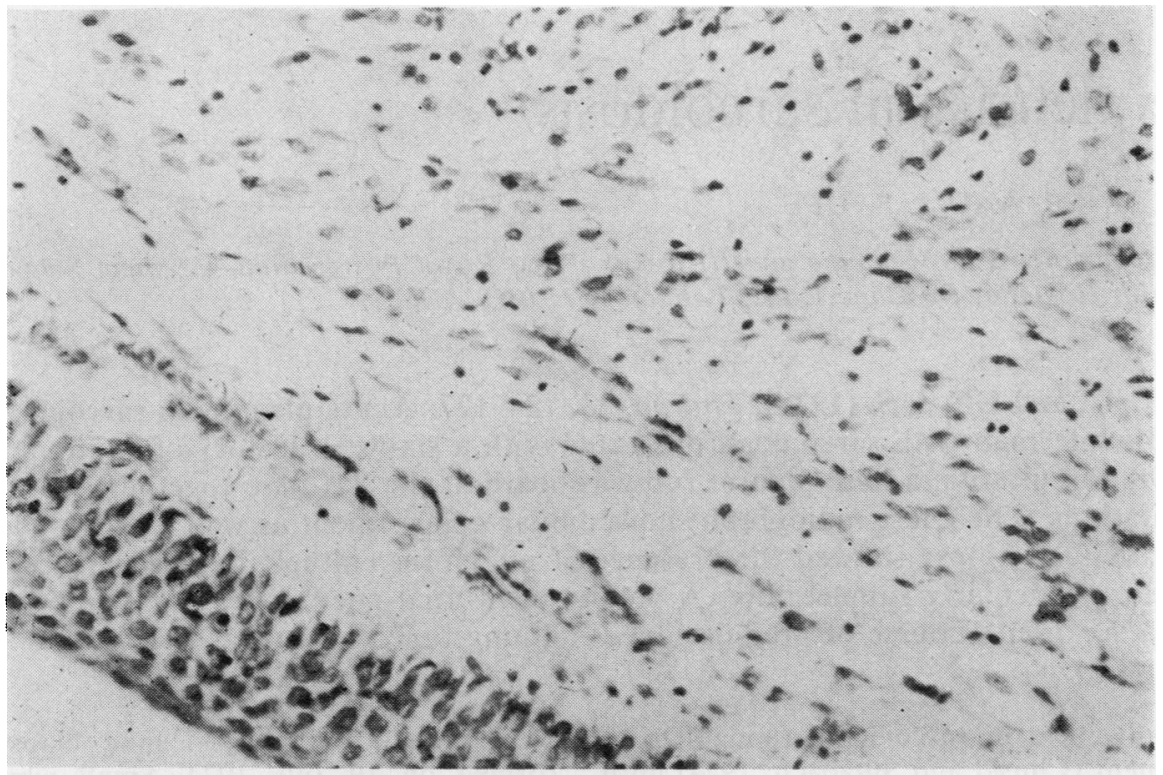

Fig. 4 Directly over the tumour tissue (Antoni B cells) there is squamous metaplasia of the tracheal epithelium ( $H$ and $E \times 250$ ).

(Antoni type B) (Fig. 4). There is tracheal epithelium directly over the tumour and there is some squamous-cell metaplasia (Fig. 4).

The tumour was completely removed under direct vision via the larynx. The stalk in the left lateral wall was cauterised. The patient's symptoms completely disappeared after the operation. He was frequently seen for follow-up and the trachea appeared to be soundly healed at repeated bronchoscopy.

Spirometry on 6 January 1977 showed normal PEF values but there was still some reduction in $\mathrm{MEF}_{25}$ and $\mathrm{MEF}_{75}$.

\section{Discussion}

A benign neurofibroma, behaving as an obstructing body, was found in this patient. The symptoms were mainly ascribed to his smoking habits. Shortness of breath after coughing appeared when the tracheal obstruction became severe.

Spirometry was quite compatible with upper airways obstruction. The persistently reduced $\mathrm{MEF}_{50}$ and $\mathrm{MEF}_{75}$ vital capacity rates after the operation can be explained by spasm of the smallest airways seen after excessive cigarette smoking
(Stanescu, 1976). The suspected diagnosis was confirmed by frozen section, which would be advisable in similar circumstances in order to confirm the nature of the tumour. A benign tumour can simply be resected; a malignant tumour requires more extensive surgical procedures.

\section{References}

Link, R. (1964). Tumoren der Trachea und der Bronchien. In Hals-Nasen-Ohren-Heilkunde, Vol. I, edited by J. Berendes, R. Link, and F. Zöllner, pp. 688-728. Thieme, Stuttgart.

Miller, R. D., and Hyatt, R. E. (1973). Evaluation of obstructing lesions of the trachea and larynx by flow-volume loops. American Review of Respiratory Disease, 108, 475-481.

Secrétan, J. P., and de Weck, L. (1953). D'un neurinome de la trachée et quelques cas de tumeurs bronchiques. Schweizerische medizinische Wochenschrift, 83, 1119.

Stanescu, D. C. (1976). Early Detection of Chronic Bronchitis and Emphysema, pp. 34-44. Stenfert Kroese, Leiden.

Requests for reprints to: Dr. F. Maesen, Department of Respiratory Diseases, de Wever-Ziekenhuis, Heerlen, The Netherlands. 